\title{
Association of Frailty with recovery from disability among community-dwelling Chinese older adults: China health and retirement longitudinal study
}

Weihao $\mathrm{Xu}^{1+}, \mathrm{Ya}-\mathrm{Xi} \mathrm{Li}^{2 \dagger}$, Yixin $\mathrm{Hu}^{3}$ and Chenkai $\mathrm{Wu}^{2,4^{*}}$

\begin{abstract}
Backgrounds: Little is known about the role of frailty in the recovery process of disability among older adults. We examined the association between frailty and recovery from activities of daily living (ADL) and instrumental ADL (IADL) disability among community-dwelling Chinese older adults.

Methods: Data were from the China Health and Retirement Longitudinal Study. Three waves were used. Participants $\geq 60$ years, had frailty assessment at baseline, and had incident disability in ADL or IADL in 2013, and had disability assessment in 2015 were included. Recovery from ADL and IADL disability were used as outcome measure. Multivariable logistic regression was used to evaluate the potential association between frailty and recovery from $A D L$ or $I A D L$.

Results: We included 516 and 598 participants in the ADL and IADL analysis, respectively. In total, 237 participants recovered from ADL disability and 293 recovered from IADL disability. Nearly half of the non-frail persons recovered from ADL disability, while less than one-quarter of the frail persons had recovery. Over half of the non-frail persons had IADL disability recovery, while only $30 \%$ of the frail recovered. After adjustment, the odds of recovery from ADL disability were 59\% (95\% confidence interval [CI]: 1, 83\%) lower among frail participants than those who were nonfrail; the odds of recovery from IADL disability were 52\% lower among frail persons than those who were non-frail and the association did not reach statistical significance.
\end{abstract}

Conclusions: Frailty is an independent predictor of poor recovery from disability among nondisabled communitydwelling older adults in China.

Keywords: Frailty, Recovery, Activities of daily living, Instrumental activities of daily living, Disability, Cohort study

* Correspondence: chenkai.wu@dukekunshan.edu.cn

tWeihao Xu and Ya-Xi Li contributed equally to this work.

${ }^{2}$ Global Health Research Center, Duke Kunshan University, Academic Building

3038, No. 8 Duke Avenue, Kunshan 215316, Jiangsu, China

${ }^{4}$ Duke Global Health Institute, Duke University, Durham, NC, USA

Full list of author information is available at the end of the article

(c) The Author(s). 2020 Open Access This article is licensed under a Creative Commons Attribution 4.0 International License, which permits use, sharing, adaptation, distribution and reproduction in any medium or format, as long as you give appropriate credit to the original author(s) and the source, provide a link to the Creative Commons licence, and indicate if changes were made. The images or other third party material in this article are included in the article's Creative Commons licence, unless indicated otherwise in a credit line to the material. If material is not included in the article's Creative Commons licence and your intended use is not permitted by statutory regulation or exceeds the permitted use, you will need to obtain permission directly from the copyright holder. To view a copy of this licence, visit http://creativecommons.org/licenses/by/4.0/. The Creative Commons Public Domain Dedication waiver (http://creativecommons.org/publicdomain/zero/1.0/) applies to the data made available in this article, unless otherwise stated in a credit line to the data. 


\section{Background}

The prevalence of disability in activities of daily living (ADLs) and instrumental ADL (IADLs) has declined during the past several decades in China [1-3]. This promising trend, however, appears to have slowed recently, primarily due to China's rapidly growing older population. In 2013, over 202 million people were over the age of 60 years in China and the number is projected to nearly double by 2040 (402 million) [4,5]. The number of disabled older adults was 37.5 million in 2013, and this number will reach 100 million in 2050 [6]. Disability in ADL and IADL is associated with increased risk of hospitalization, lower quality of life, and shorter life expectancy, placing a substantial burden on older people, their caregivers, and the health care system [710].

A growing body of literature has suggested that disability is a dynamic rather than static process and transitions among different states of disability are common [11-15]. Prior studies have identified frailty-a clinical syndrome characterized by decreased resilience to stressors and high vulnerability for adverse health outcomes-as a risk factor for poor recovery of independence in ADL among U.S. older adults [16]. However, to our knowledge, little is known about the role of frailty in the recovery process of disability among older adults in developing countries including China. In addition, while previous studies focused on ADL recovery, much less attention has been paid to IADL recovery. ADL and IADL measure different aspects of functional capacity of older adults. ADL includes basic and core self-care tasks (e.g., eating, dressing, bathing), while IADL represents more complicated and higher-level tasks that are necessary for independently adapting to the living environment (e.g., cooking, shopping, taking medication) $[17,18]$. Both theory and empirical evidence suggest a hierarchical relationship between IADL and ADL, with older persons first declining in IADL function [19]. Therefore, identification of factors associated with IADL recovery is critical for designing effective interventions in the early stage of the recovery process among the disabled persons.

In the present study, we examined the association between frailty and recovery from ADL and IADL disability among community-dwelling Chinese older adults without pre-existing disability from the China Health and Retirement Longitudinal Study (CHARLS). We hypothesized that frail older adults would have lower ability to recover from disability than non-frail ones.

\section{Methods}

\section{Data and participants}

Data are from the CHARLS, an ongoing longitudinal cohort study of a nationally representative sample of community-dwelling adults from 28 provinces of China.
A total of 17,708 residents aged 45 years or older were interviewed at baseline (2011-2012), with a response rate at $80.5 \%$, and followed every two years afterwards (2013-2014 and 2015-2016 waves). All participants gave informed consent; the protocol was approved by the Ethical Review Committee at the Peking University. Further details about the recruitment strategies and study design have been published elsewhere [20].

Frailty was measured at baseline (2011-2012); data on disability were collected at baseline and two follow-ups. We included participants who (i) were $\geq 60$ years old, (ii) had frailty assessment at baseline, (iii) had no disability in 2011, (iii) were disabled in 2013, and (iv) had disability assessment in 2015. Among 611 participants who had frailty assessment and were not disabled in ADL in 2011, and developed ADL disability in 2013, we excluded 95 individuals who were lost to follow-up, resulting to an analytic sample of 516 for ADL analysis. Among 701 participants who had frailty assessment and were not disabled in IADL in 2011, and developed IADL disability in 2013, 103 individuals were lost to follow-up, leading an analytic sample of 598 for IADL analysis.

\section{Frailty}

Frailty was assessed by a modified version of the Fried's Physical Frailty Phenotype (PFP) [21], which was originally developed in the Cardiovascular Health Study. Five criteria were included: slowness, weakness, exhaustion, inactivity, and shrinking (Table 1). This assessment has been developed and validated in the CHARLS to examine the epidemiology and natural history of frailty among community-dwelling older adults in China [22-24].

Slowness was measured by usual gait speed over a 2.5$\mathrm{m}$ course. Two trials were performed and the average walking time was used to calculate gait speed $(\mathrm{m} / \mathrm{s})$.

Table 1 Cut-points for defining slowness and weakness

\begin{tabular}{|c|c|c|}
\hline \multicolumn{3}{|c|}{ Gait speed over a 2.5 -m course: } \\
\hline & Men with height $\leq 163 \mathrm{~cm}$ & $\leq 0.45 \mathrm{~m} / \mathrm{s}$ \\
\hline \multirow[t]{3}{*}{ Slowness } & Men with height $>163 \mathrm{~cm}$ & $\leq 0.48 \mathrm{~m} / \mathrm{s}$ \\
\hline & Women with height $\leq 163 \mathrm{~cm}$ & $\leq 0.36 \mathrm{~m} / \mathrm{s}$ \\
\hline & Women with height $>163 \mathrm{~cm}$ & $\leq 0.43 \mathrm{~m} / \mathrm{s}$ \\
\hline \multicolumn{3}{|c|}{ Grip strength $(\mathrm{kg})$ : } \\
\hline & Men with $\mathrm{BMI} \leq 20.6 \mathrm{~kg} / \mathbf{m}^{2}$ & $\leq 25.2 \mathrm{~kg}$ \\
\hline & Men with BMI $20.6-23.2 \mathrm{~kg} / \mathbf{~ m}^{2}$ & $\leq 28.5 \mathrm{~kg}$ \\
\hline & Men with BMI $23.2-25.9 \mathrm{~kg} / \mathbf{~ m}^{2}$ & $\leq 30.0 \mathrm{~kg}$ \\
\hline \multirow[t]{5}{*}{ Weakness } & Men with $\mathrm{BMI} \geq 25.9 \mathrm{~kg} / \mathbf{m}^{\mathbf{2}}$ & $\leq 30.0 \mathrm{~kg}$ \\
\hline & Women with $\mathrm{BMI} \leq 20.0 \mathrm{~kg} / \mathbf{~ m}^{2}$ & $\leq 15.0 \mathrm{~kg}$ \\
\hline & Women with BMI $20.0-22.1 \mathrm{~kg} / \mathbf{~ m}^{2}$ & $\leq 17.5 \mathrm{~kg}$ \\
\hline & Women with BMI $22.1-24.8 \mathrm{~kg} / \mathbf{~ m}^{2}$ & $\leq 17.5 \mathrm{~kg}$ \\
\hline & Women with $\mathrm{BMl}>24.8 \mathrm{~kg} / \mathrm{m}^{2}$ & $\leq 20.0 \mathrm{~kg}$ \\
\hline
\end{tabular}


Slowness was defined as sex- and height-specific gait speed $\leq 20$ th percentile of the weighted sample distribution [24]. Handgrip strength was measured by dynamometer. Two trials for each hand were performed, and the maximum of four trials was used. Weakness was defined as handgrip strength $\leq 20$ th percentile of the weighted sample distribution, adjusting for sex and body mass index (BMI) [24]. Self-reported exhaustion was assessed by two questions in the Center for Epidemiological Studies-Depression scale (CES-D) scale [25]: I felt everything I did was an effort." and "I could not get going." Exhaustion was identified if a person answered "A moderate amount of time; 3 to 4 days" or "Most of the time; 5 to 7 days" to either of the two questions. Physical inactivity was defined if a person self-reported that he/ she walked $<10$ min continuously during a usual week. Shrinking was identified if a person reported losing $\geq 5$ $\mathrm{kg}$ in prior year or had a BMI $\leq 18.5 \mathrm{~kg} / \mathrm{m}^{2}$ (calculated based on measured standing height and body weight).

Frailty was categorized into non-frail, prefrail, and frail according to the number of criteria met. Non-frail was defined when none of the criteria was met; prefrail was defined when one or two criteria were met; frail was defined when three to five criteria were met.

\section{Outcomes}

Disability was assessed using five ADL tasks (dressing, bathing, eating, getting out of bed, and toileting) and five IADL) tasks (preparing hot meals, doing household chores, shopping, managing assets, and taking medications), by asking "Do you have difficulty in" performing the task? Participants who answered "I have difficulty but can still do it", "Yes, I have difficulty and need help", or "I cannot do it" to one or more tasks were considered having ADL or IADL disability. Recovery from ADL (or IADL) disability was defined as regaining independence in all ADLs (or IADLs) in 2015 after being disabled in 2013.

\section{Covariates}

Demographic factors included age, sex, education (no formal education, did not finish elementary school, sishu or elementary school, or middle school or higher), and marital status (married vs. not married). Smoking status was categorized as never, former or current smokers. Body mass index (BMI) was calculated as weight (kilograms) divided by height (meters) squared, and classified into underweight $(\mathrm{BMI}<18.5)$, normal $\quad(\mathrm{BMI}=18.5-24.0)$, overweight $(\mathrm{BMI}=24.0-28.0)$, and obese $(\mathrm{BMI} \geq 28.0)$ [26]. History of hypertension, cardiac disease (coronary heart disease, angina, heart failure, myocardial infarction, and other heart diseases), stroke, diabetes, chronic lung diseases, kidney disease, digestive disease, liver disease, cancer (not including minor skin cancers), and arthritis or rheumatism was assessed based on self-reported physician diagnosis. The total number of chronic conditions, ranging from 0 to 10, was used in further analyses. Cognitive function was assessed by the Telephone Interview for Cognitive Status (TICS) [27, 28], a telephone-based cognitive screening instrument. The reliability and validity of the TICS has been demonstrated in different populations and settings [29-32]. Depression was assessed using the modified 10-item CES-D scale [13] excluding two items used for identifying exhaustion (a frailty component) [20]. Severe disability (vs. mild) was defined as having difficulty in $\geq 2$ ADLs or IADLs.

\section{Statistical analysis}

We first described the baseline characteristics of participants included in the ADL analysis $(n=516)$ and IADL analysis $(n=598)$, separately. We used logistic regression models to examine the association between frailty (nonfrail, prefrail, and frail) and recovery from disability. Age, sex, and disability severity (severe vs. mild) were included in the minimally adjusted models; education, marital status, BMI, smoking status, depression, cognitive function, and number of chronic conditions were additionally adjusted in the fully adjusted models. ADL and IADL were analyzed separately. In addition, we examined the association between frailty and recovery from IADL disability among 336 persons who had incident IADL disability in 2013 but did not have any difficulty in ADLs. All covariates were measured at the time of frailty assessment instead of at the most recent assessment of covariates prior to the onset of incident disability because covariates measured after frailty could be in the causal pathway between frailty and disability recovery. Adjustment for such mediators could lead to underestimation of the overall effect of frailty.

All tests were two-sided with a significance level of 0.05. We performed all analyses using Stata 15.0 (Stata Corp, College Station, TX).

\section{Results}

\section{Sample description}

We included 516 and 598 participants in the ADL and IADL analysis, respectively. Among participants included in the ADL analysis, $62.0 \%$ were $60-69$ years of age, $57.4 \%$ were female, and $74.2 \%$ were married/living together; $37.8,55.4$, and $6.8 \%$ were non-frail, prefrail, and frail, respectively (Table 2). The distribution of sociodemographic, lifestyle, and health characteristics was similar among persons included in the IADL analysis.

\section{Association between frailty and recovery from ADL disability}

Of the 516 participants who had incident ADL disability, 237 (45.9\%) recovered within 2 years (Table 3). Older 
Table 2 Characteristics of study participants

\begin{tabular}{|c|c|c|}
\hline & $\begin{array}{l}\mathrm{ADL} \\
\text { analysis }\end{array}$ & $\begin{array}{l}\text { IADL } \\
\text { analysis } \\
\end{array}$ \\
\hline Characteristics & $N=516$ & $N=598$ \\
\hline \multicolumn{3}{|l|}{ Age, years, No (\%) } \\
\hline $60-64$ & $202(39.1)$ & $229(38.3)$ \\
\hline $65-69$ & $118(22.9)$ & $142(23.7)$ \\
\hline $70-74$ & 96 (18.6) & 117 (19.6) \\
\hline $75-79$ & $68(13.2)$ & $78(13.0)$ \\
\hline $80+$ & $32(6.2)$ & $32(5.4)$ \\
\hline Female, No. (\%) & $296(57.4)$ & $322(53.8)$ \\
\hline \multicolumn{3}{|l|}{ Education, No. (\%) } \\
\hline No formal education/illiterate & $216(41.9)$ & $259(43.3)$ \\
\hline Did not finish elementary school & $116(22.5)$ & $132(22.1)$ \\
\hline Sishu or elementary school & $135(26.2)$ & $137(22.9)$ \\
\hline Middle school or above & $49(9.5)$ & $70(11.7)$ \\
\hline \multicolumn{3}{|l|}{ Marital Status, No. (\%) } \\
\hline Married/living together & $383(74.2)$ & $469(78.4)$ \\
\hline \multicolumn{3}{|l|}{ Smoking status, No. (\%) } \\
\hline Never & $314(60.9)$ & $357(59.7)$ \\
\hline Former & $58(11.2)$ & $72(12.0)$ \\
\hline Current & $144(27.9)$ & $169(28.3)$ \\
\hline \multicolumn{3}{|l|}{ Body mass index, $\mathrm{kg} / \mathrm{m}^{2}$} \\
\hline Underweight, №. (\%) & $56(10.9)$ & $70(11.7)$ \\
\hline Normal, No. (\%) & $275(53.3)$ & $330(55.2)$ \\
\hline Overweight, No. (\%) & $127(24.6)$ & $135(22.6)$ \\
\hline Obese, No. (\%) & $58(11.2)$ & $63(10.5)$ \\
\hline Number of chronic conditions, mean (SD) & $1.6(1.2)$ & $1.5(1.2)$ \\
\hline Cognitive function ${ }^{a}$, mean (SD) & $10.2(5.5)$ & $10.4(5.4)$ \\
\hline \multicolumn{3}{|l|}{ Frailty, No. (\%) } \\
\hline Non-frail & $195(37.8)$ & $228(38.1)$ \\
\hline Prefrail & $286(55.4)$ & $330(55.2)$ \\
\hline Frail & $35(6.8)$ & $40(6.7)$ \\
\hline Severe disability ${ }^{b}$, No. (\%) & 199 (38.6) & $280(46.8)$ \\
\hline
\end{tabular}

adults with different levels of frailty had different likelihood of recovering from ADL disability. Nearly half of the non-frail persons recovered, while only about onequarter of the frail persons had recovery. After multivariable adjustment, the odds of recovery from ADL disability were $59 \%$ (95\% confidence interval [CI]: 1, 83\%) lower among frail participants than those who were non-frail. We did not observe statistically significant difference in recovery between non-frail and prefrail persons.
Table 3 Frailty status and recovery from ADL disability

\begin{tabular}{|c|c|c|c|}
\hline \multirow[t]{2}{*}{$N=516$} & \multirow{2}{*}{$\begin{array}{l}\text { Recovered } \\
\text { No. (\%) }\end{array}$} & \multicolumn{2}{|l|}{ Odds ratio $(95 \% \mathrm{Cl})$} \\
\hline & & Minimally Adjusted $^{a}$ & Fully Adjusted $^{b}$ \\
\hline Total & $237(45.9)$ & & \\
\hline \multicolumn{4}{|l|}{ Frailty } \\
\hline Non-frail & $97(49.7)$ & Ref. & Ref. \\
\hline Prefrail & $131(45.8)$ & $0.94(0.65,1.38)$ & $0.93(0.62,1.39)$ \\
\hline Frail & $9(25.7)$ & $0.45(0.19,1.03)$ & $0.41(0.17,0.99)$ \\
\hline
\end{tabular}

Abbreviations: $\mathrm{Cl}$ confidence interval, $A D L$ activities of daily living Notes: Participants who died in the following visit after the onset of incident disability were included and considered not to recover. Participants who were alive but not interviewed in the following visit after the onset of incident disability were excluded

${ }^{a}$ Age, sex, and severity of ADL disability (1 vs. $2+$ difficulties)

${ }^{b}$ Age, sex, severity of ADL disability (1 vs. $2+$ difficulties), education, marital status, BMI, smoking status, CESD, cognition, and number of chronic conditions

\section{Association between frailty and recovery from IADL disability}

Recovery from IADL disability within 2 years was observed for 293 (49.0\%) of the 598 newly disabled participants (Table 4). The likelihood of recovery decreased steadily from non-frail to frail. Over half of the non-frail persons had recovery, while only $30 \%$ of the frail recovered. Among females, $58.1 \%$ of the frail, $45.7 \%$ of the prefrail, and $24.0 \%$ of the non-frail recovered from IADL disability. The association was weaker among males; $50.0,49.7$, and $40 \%$ of the frail, prefrail, and non-frail recovered, respectively. After adjusting for age, sex, and severity of IADL disability, the odds of recovery were $58 \%$ (95\% CI: 10, 80\%) lower among frail participants than the non-frail. In the fully adjusted model, the association between frailty and recovery from IADL disability was slightly attenuated. The odds of recovery were $52 \%$ lower among frail persons than those who were non-frail and the association did not reach statistical significance.

Table 4 Frailty status and recovery from IADL disability

\begin{tabular}{|c|c|c|c|}
\hline \multirow[t]{2}{*}{$N=598$} & \multirow{2}{*}{$\begin{array}{l}\text { Recovered } \\
\text { No. (\%) }\end{array}$} & \multicolumn{2}{|l|}{ Odds ratio $(95 \% \mathrm{Cl})$} \\
\hline & & Minimally Adjusted $^{a}$ & Fully Adjusted $^{b}$ \\
\hline Total & $293(49.0)$ & & \\
\hline \multicolumn{4}{|l|}{ Frailty } \\
\hline Non-frail & $124(54.4)$ & Ref. & Ref. \\
\hline Prefrail & $157(47.6)$ & $0.79(0.56,1.12)$ & $0.88(0.61,1.27)$ \\
\hline Frail & $12(30.0)$ & $0.42(0.20,0.90)$ & $0.48(0.21,1.07)$ \\
\hline
\end{tabular}

Abbreviations: $\mathrm{Cl}$ confidence interval, IADL instrumental activities of daily living Notes: Participants who died in the following visit after the onset of incident disability were included and considered not to recover. Participants who were alive but not interviewed in the following visit after the onset of incident disability were excluded

a age, sex, and severity of IADL disability (1 vs. $2+$ difficulties)

b age, sex, severity of IADL disability (1 vs. 2+ difficulties), education, marital status, BMI, smoking status, CESD, cognition, and number of chronic conditions 
Of the 336 persons who were newly disabled in IADL but were free of ADL disability, 196 (58.3\%) recovered within 2 years (Table 5 ). The chance of recovery differed among persons with different levels of frailty; 67.2, 53.9, and $40.0 \%$ of the non-frail, prefrail, and frail participants had recovery, respectively. In the adjusted models, prefrail and frail persons had lower odds of recovery than the non-frail, although the associations were not statistically significant.

\section{Discussion}

In this community-based prospective cohort study, we found that frailty was associated with poor recovery from ADL and IADL disability among newly disabled Chinese older adults; once they were newly disabled, non-frail elders had a higher chance of recovering were than the frail. These results provided additional evidence supporting the importance of frailty-a clinical syndrome of reduced reserve to stressors-in the recovery process of disability among older adults.

Our results were in line with several prior studies conducted in the US, showing that frail older adults were less likely to regain independence of ADL after being disabled than the non-frail. Using data from two large U.S. cohort studies-Cardiovascular Health Study and Health and Retirement Study, we demonstrated that frailty was an independent risk factor for poor recovery of ADL function [16]. Using data from 457 moderately or severely disabled community-dwelling older women enrolled in the Women's Health and Aging Study, Boyd and colleagues showed that frailty was an independent risk factor for decline in ADL independence after a hospitalization [33]. In addition to frailty assessments incorporating multiple components (e.g., physical frailty phenotype approach), several studies have demonstrated the predictive value of individual frailty components, including slow gait speed, low physical activity level, and

Table 5 Frailty status and recovery from IADL disability among persons who were not disabled in ADL

\begin{tabular}{llll}
\hline$N=336$ & $\begin{array}{l}\text { Recovered } \\
\text { No. }(\%)\end{array}$ & \multicolumn{2}{l}{ Odds ratio $(95 \% \mathrm{Cl})$} \\
\cline { 4 - 4 } & & Minimally Adjusted $^{\mathrm{a}}$ & Fully Adjusted $^{\mathrm{b}}$ \\
\hline Frailty & & & \\
Non-frail & $90(67.2)$ & Ref. & Ref. \\
Prefrail & $98(53.9)$ & $0.60(0.36,0.96)$ & $0.66(0.40,1.09)$ \\
Frail & $8(40.0)$ & $0.45(0.16,1.23)$ & $0.52(0.17,1.59)$ \\
\hline
\end{tabular}

Abbreviations: $\mathrm{Cl}$ confidence interval

Notes: Participants who died in the following visit after the onset of incident disability were included and considered not to recover. Participants who were alive but not interviewed in the following visit after the onset of incident disability were excluded

${ }^{\text {a }}$ Age, sex, and severity of IADL disability (1 vs. $2+$ difficulties)

${ }^{b}$ Age, sex, severity of IADL disability (1 vs. 2+ difficulties), education, marital status, BMI, smoking status, depression, cognition measured by mini-mental status examination, and number of chronic conditions significant weight loss, for recovery after being disabled among the elderly $[13,14,34]$. The present study extended previous research by highlighting the importance of frailty in the recovery process of ADL disability among Chinese older adults, which constitute the largest older population in the world.

There was suggestive evidence that frailty is associated with poor recovery from IADL disability among newly disabled Chinese older adults. We found that over half of the non-frail persons regained independence in IADL function, whereas only three out of ten frail one recovered. Our study builds on several earlier investigations examining risk factors for IADL recovery. In a study of older adults from five communities in the UK, Seidel et al. found that poor self-reported health and high burden of comorbidity were associated with poor recovery of IADL function [35]. Using data from 1656 persons aged 50 years or above in the UK, d'Orsi and colleagues found that vigorous physical activity and good self-rated memory were associated with higher likelihood of IADL recovery [36]. The present study provides new insight into understanding of the recovery process of IADL disability. The association between frailty and recovery from IADL disability was more evident among older women than men. One plausible explanation is that performing IADL tasks-for example, preparing hot meals and doing household chores-may be challenging even for non-disabled older men because women usually take on these domestic responsibilities. In other words, some older men were classified as being IADL disabled because they did not have the knowledge or skills to perform these activities.

We found that frailty precluded disability recoveryfrail older adults were much less likely to recover from disability than the nonfrail. There are several plausible explanations for this phenomenon. First, one defining feature of frailty is reduced reserve and increased vulnerability to stressors. Frail persons with incident disability have compromised ability to deal with this daily stressor and, therefore, less likely to regain independence. Frailty involves declines in gait speed and muscle strength, both of which are critical for performing ADL and IADL. Second, older adults who are frail often have other health problems-such as poor nutrition status, increased level of inflammation-that might hamper disability recovery [37-39]. Therefore, interventions targeting both frailty or frailty components and co-occurring health issues may be important for disabled older adults to regain independence.

Strength of our study include its use of nationally representative sample, prospective design, well validated frailty assessment, comprehensive measurements of confounders, and heterogeneous socio-demographic composition of the study participants. To our knowledge, 
this study is the first to examine the association between frailty and recovery of ADL and IADL functions among older adults in China. This study is not without limitations. First, the frailty assessment was only administered once; we could not rule out the possibility that there would be unobserved transitions during the follow-up period and we were unable to differentiate transient frailty (more subject to measurement error) and persistent frailty. In addition, we excluded elders who were initially disabled because of the fundamental differences between primary frailty and secondary frailty induced by disability. Moreover, although the modified version of the PFP approach has been validated among Chinese older adults, modifying the criteria could potentially lead to misclassification of frailty status [40]. Furthermore, both ADL and IADL performance were assessed based on self-reports by the participants, which might be different from objective measures. However, it has been demonstrated that the concordance between selfreported disability and objective measures is high [4143]. Lastly, residual confounding is an inevitable issue in observational studies.

\section{Conclusion}

In summary, we examined the association between frailty, assessed by the PFP scale, and recovery from ADL and IADL disability among community-dwelling older adults in China. Our results provided additional evidence that frailty is an independent predictor of regaining independence after being disabled and demonstrated the construct validity of the PFP scale for assessing frailty, a clinical syndrome characterized by reduced reserve and resilience to stressors. Most of the frailty instruments were validated for predictive validity only. We found that frailty, as assessed by the PFP approach, independently modified older adults' ability to recovery from disability. This type of empirical investigation has been considered the best way to evaluate the validity of a frailty assessment [44]. Taken together with previous work [45-47], there is strong evidence of the validity of the PFP approach for measuring frailty. Assessment of frailty may help clinicians to better focus their efforts in promoting functional recovery after experiencing a stressful event.

\section{Abbreviations}

ADL: Activities of daily life; IADL: Instrumental activities of daily life; Cl: Confidence interval; CHARLS: China Health and Retirement Longitudinal Study; PFP: Physical frailty phenotype; BMI: Body mass index; CES-D: Center for epidemiologic studies - depression Scale; TICS: Telephone interview for cognitive status

\section{Acknowledgements}

We thank the China Center for Economic Research, the National School of Development of Peking University for providing the data.

\section{Authors' contributions}

Study concept and design: CKW. Acquisition of data: CKW, YXH. Analysis and interpretation of data: WHX, YXL, YXH. Drafting of the manuscript: WHX, YXL. Critical revision of the manuscript for important intellectual content: $W H X$,

CKW. All authors read and approved the final manuscript.

\section{Funding}

Suzhou Science and Technology Bureau SS2019069. The research results of this article are sponsored partly by the Kunshan Municipal Government research funding.

The funder played no role in study design, data collection, and analysis, the decision to publish, or preparation of the manuscript.

Availability of data and materials

The raw data is available on website (http://charls.pku.edu.cn/en).

Ethics approval and consent to participate

The study design was approved by the ethical review committee of Peking University. All participants gave written informed consent.

Consent for publication

Not applicable.

\section{Competing interests}

Dr. Chenkai Wu provides paid consultative services to Health Keepers, a health data analytics start-up in China.

\section{Author details \\ ${ }^{1}$ Geriatric Cardiology Department of the Second Medical Center \& National Clinical Research Center for Geriatric Diseases, Chinese PLA General Hospital, Beijing, China. ${ }^{2}$ Global Health Research Center, Duke Kunshan University, Academic Building 3038, No. 8 Duke Avenue, Kunshan 215316, Jiangsu, China. ${ }^{3}$ Geriatric Health Care Department of The Second Medical Center \& National Clinical Research Center for Geriatric Diseases, Chinese PLA General Hospital, Beijing, China. ${ }^{4}$ Duke Global Health Institute, Duke University, Durham, NC, USA.}

Received: 20 August 2019 Accepted: 16 March 2020

Published online: 30 March 2020

\section{References}

1. Liang Y, Song A, Du S, Guralnik JM, Qiu C. Trends in disability in activities of daily living among Chinese older adults, 1997-2006: the China health and nutrition survey. J Gerontol A Biol Sci Med Sci. 2015;70(6):739-45.

2. Liang Y, Welmer AK, Möller J, Qiu C. Trends in disability of instrumental activities of daily living among older Chinese adults, 1997-2006: population based study. BMJ Open. 2017:7(8):e016996.

3. Liang Y, Welmer AK, Wang R, Song A, Fratiglioni L, Qiu C. Trends in incidence of disability in activities of daily living in Chinese older adults: 1993-2006. J Am Geriatr Soc. 2017;65(2):306-12.

4. DeSA U. World population prospects: the 2012 revision. New York: Population Division of the Department of Economic and Social Affairs of the United Nations Secretariat; 2013.

5. Wu Y, Dang J. Blue book of aging: China report of the development on aging cause (2013). Beijing: Social Sciences Academic Press (China); 2013.

6. Dang J, Wu Y, Liu N. Survey report on the living conditions of China's urban and rural older persons. Beijing: Social Sciences Academic Press; 2018.

7. Harrow BS, Tennstedt SL, McKinlay JB. How costly is it to care for disabled elders in a community setting? Gerontologist. 1995;35(6):803-13.

8. Manton KG. A longitudinal study of functional change and mortality in the United States. J Gerontol. 1988;43(5):S153-61.

9. Gill TM, Robison JT, Tinetti ME. Difficulty and dependence: two components of the disability continuum among community-living older persons. Ann Intern Med. 1998;128(2):96-101.

10. Fried LP, Kronmal RA, Newman AB, et al. Risk factors for 5-year mortality in older adults: the Cardiovascular Health Study. JAMA. 1998;279(8):585-92.

11. Romoren TI, Blekeseaune M. Trajectories of disability among the oldest old. J Aging Health. 2003;15(3):548-66.

12. Lunney JR, Lynn J, Foley DJ, Lipson S, Guralnik JM. Patterns of functiona decline at the end of life. JAMA. 2003;289(18):2387-92. 
13. Hardy SE, Gill TM. Factors associated with recovery of independence among newly disabled older persons. Arch Intern Med. 2005;165(1):106-12.

14. Hardy SE, Gill TM. Recovery from disability among community-dwelling older persons. JAMA. 2004;291(13):1596-602.

15. Gill TM, Gahbauer EA, Han L, Allore HG. Trajectories of disability in the last year of life. N Engl J Med. 2010;362(13):1173-80.

16. Wu C, Kim DH, Xue QL, Lee DSH, Varadhan R, Odden MC. Association of frailty with recovery from disability among community-dwelling older adults: results from two large U.S. cohorts. J Gerontol A Biol Sci Med Sci. 2019;74(4):575-81.

17. Katz S, Ford AB, Moskowitz RW, Jackson BA, Jaffe MW. Studies of illness in the aged. The index of ADL: a standardized measure of biological and psychosocial function. JAMA. 1963;185:914-9.

18. Lawton MP, Brody EM. Assessment of older people: self-maintaining and instrumental activities of daily living. Gerontologist. 1969;9(3):179-86.

19. Spector WD, Katz S, Murphy JB, Fulton JP. The hierarchical relationship between activities of daily living and instrumental activities of daily living. J Chronic Dis. 1987;40(6):481-9.

20. Zhao Y, Hu Y, Smith JP, Strauss J, Yang G. Cohort profile: the China health and retirement longitudinal study (CHARLS). Int J Epidemiol. 2014;43(1):61-8

21. Fried LP, Tangen CM, Walston J, et al. Frailty in older adults: evidence for a phenotype. J Gerontol A Biol Sci Med Sci. 2001;56(3):M146-56.

22. Li Y, Xue QL, Odden MC, Chen X, Wu C. Linking early life risk factors to frailty in old age: evidence from the China Health and Retirement Longitudinal Study. Age Ageing. 2020;49(2):208-17.

23. $X u$ W, Li YX, Wu C. Incidence of frailty among community-dwelling older adults: a nationally representative profile in China. BMC Geriatr. 2019;19(1): 378.

24. Wu C, Smit E, Xue QL, Odden MC. Prevalence and correlates of frailty among community-dwelling Chinese older adults: the China health and retirement longitudinal study. J Gerontol A Biol Sci Med Sci. 2017;73(1): 102-8.

25. Radloff LS, et al. Appl Psychol Meas. 1977;1:385-401.

26. Chen C, Lu FC. Department of Disease Control Ministry of Health, PR China. The guidelines for prevention and control of overweight and obesity in Chinese adults. Biomed Environ Sci. 2004;17(Suppl):1-36.

27. Brandt J, Spencer M, Folstein M. The telephone interview for cognitive status. Neuropsychiatry Neuropsychol Behav Neurol. 1988;1:111-7.

28. Breitner JC, Welsh KA, Gau BA, et al. Alzheimer's disease in the National Academy of Sciences-National Research Council registry of aging twin veterans. III. Detection of cases, longitudinal results, and observations on twin concordance. Arch Neurol. 1995;52(8):763-71.

29. Seo EH, Lee DY, Kim SG, et al. Validity of the telephone interview for cognitive status (TICS) and modified TICS (TICSm) for mild cognitive imparment (MCl) and dementia screening. Arch Gerontol Geriatr. 2011;52(1): e26-30.

30. Dal Forno G, Chiovenda P, Bressi F, et al. Use of an Italian version of the telephone interview for cognitive status in Alzheimer's disease. Int J Geriatr Psychiatry. 2006;21(2):126-33.

31. Georgakis MK, Papadopoulos FC, Beratis I, et al. Validation of TICS for detection of dementia and mild cognitive impairment among individuals characterized by low levels of education or illiteracy: a population-based study in rural Greece. Clin Neuropsychol. 2017;31:sup1, 61-71.

32. Konagaya Y, Washimi Y, Hattori H, Takeda A, Watanabe T, Ohta T. Validation of the telephone interview for cognitive status (TICS) in Japanese. Int J Geriatr Psychiatry. 2007:22(7):695-700.

33. Boyd CM, Ricks M, Fried LP, et al. Functional decline and recovery of activities of daily living in hospitalized, disabled older women: the Women's health and aging study I. J Am Geriatr Soc. 2009;57(10):1757-66.

34. Gill TM, Gahbauer EA, Han L, Allore HG. Factors associated with recovery of prehospital function among older persons admitted to a nursing home with disability after an acute hospitalization. J Gerontol A Biol Sci Med Sci. 2009;64(12):1296-303.

35. Seidel D, Jagger C, Brayne C, Matthews FE, Cfas M. Recovery in instrumental activities of daily living (IADLs): findings from the Medical Research Council cognitive function and ageing study (MRC CFAS). Age Ageing. 2009;38(6): 663-8.

36. d'Orsi E, Xavier AJ, Steptoe A, et al. Socioeconomic and lifestyle factors related to instrumental activity of daily living dynamics: results from the English longitudinal study of ageing. J Am Geriatr Soc. 2014;62(9):1630-9.
37. Okamura T, Hayakawa T, Hozawa A, et al. Lower levels of serum albumin and total cholesterol associated with decline in activities of daily living and excess mortality in a 12-year cohort study of elderly Japanese. J Am Geriatr Soc. 2008:56(3):529-35.

38. Cesari M, Penninx BW, Pahor M, et al. Inflammatory markers and physical performance in older persons: the InCHIANTI study. J Gerontol A Biol Sci Med Sci. 2004:59A:242-8

39. Maraldi C, Volpato S, Cesari M, et al. Anemia and recovery from disability in activities of daily living in hospitalized older persons. J Am Geriatr Soc. 2006; 54(4):632-6.

40. Theou O, Cann L, Blodgett J, Wallace LM, Brothers TD, Rockwood K Modifications to the frailty phenotype criteria: systematic review of the current literature and investigation of 262 frailty phenotypes in the survey of health, ageing, and retirement in Europe. Ageing Res Rev. 2015;21:78-94.

41. Reuben DB, Siu AL, Kimpau S. The predictive validity of self-report and performance-based measures of function and health. J Gerontol. 1992;47(4): M106-10.

42. Magaziner J, Bassett SS, Hebel JR, Gruber-Baldini A. Use of proxies to measure health and functional status in epidemiologic studies of community-dwelling women aged 65 years and older. Am J Epidemiol. 1996;143(3):283-92.

43. Young Y, Boyd CM, Guralnik JM, Fried LP. Does self-reported function correspond to objective measures of functional impairment? J Am Med Dir Assoc. 2010;11(9):645-53.

44. Xue QL, Varadhan R. What is missing in the validation of frailty instruments? Am Med Dir Assoc. 2014;15(2):141-2.

45. Wu C, Geldhof GJ, Xue QL, Kim DH, Newman AB, Odden MC. Development, construct validity, and predictive validity of a continuous frailty scale: results from 2 large US cohorts. Am J Epidemiol. 2018;187(8):1752-62.

46. Bandeen-Roche $K$, Xue QL, Ferrucci L, et al. Phenotype of frailty: characterization in the women's health and aging studies. J Gerontol A Biol Sci Med Sci. 2006;61(3):262-6.

47. Fried LP, Xue QL, Cappola AR, et al. Nonlinear multisystem physiological dysregulation associated with frailty in older women: implications for etiology and treatment. J. Gerontol A Biol Sci Med Sci. 2009;64(10):1049-57.

\section{Publisher's Note}

Springer Nature remains neutral with regard to jurisdictional claims in published maps and institutional affiliations.

Ready to submit your research? Choose BMC and benefit from:

- fast, convenient online submission

- thorough peer review by experienced researchers in your field

- rapid publication on acceptance

- support for research data, including large and complex data types

- gold Open Access which fosters wider collaboration and increased citations

- maximum visibility for your research: over $100 \mathrm{M}$ website views per year

At BMC, research is always in progress.

Learn more biomedcentral.com/submission 